\title{
Cross-validation of TRACE and eTRACE (Formetric TRACE) for aesthetics evaluation in scoliosis patients
}

\author{
Paolo Pizzetti', Claudia Fusco, Francesco Saveri, Fabio Zaina, Stefano Negrini \\ From 7th International Conference on Conservative Management of Spinal Deformities \\ Montreal, Canada. 20-22 May 2010
}

\section{Introduction}

The aesthetic issue is one of the main aim in the treatment of Idiopathic Scoliosis (IS) as defined by SOSORT. TRACE is a tool, recently developed, which standardize the subjective medical experts evaluation and has shown a fair sensitivity and repeatability in the everyday clinical setting for the evaluation of aesthetics in IS patients. Recently, it was also successfully investigated the possibility to introduce a set of objectives aesthetic parameters obtained by 3D reconstruction of the shape of the back of IS patients through surface topography by Formetric (eTRACE). Since there is no gold-standard for aesthetic evaluation of IS, a correlation between two existing measures allow to validate them as measurements tool of the same underlying physiological phenomenon. Our aim was to evaluate if there was a correlation between TRACE and e-TRACE.

\section{Materials and methods}

The eTRACE of 30 scoliotic patients were obtained by $3 \mathrm{D}$ reconstruction via 4D Formetric device. TRACE have been blindly collected from the Formetric images of the same patients two times by three MD who regularly use TRACE in their daily practice. We calculated the correlation among TRACE and eTRACE. Then, to verify if high values of TRACE corresponded to high one of eTRACE, the population was divided in groups for the different sub-scales of TRACE and parameters of eTRACE and differences searched through appropriate statistics.

\section{Results}

We found strong correlations for most of the waist parameters ( $\mathrm{R}$ range $0,476-0,856, \mathrm{Rq} 0,227-0,732$ ), good for scapulae (with thoracic torsion: R 0,458 - Rq 0,210) and hemithorax ( 0,466 - Rq 0,217), fable for shoulders (with height difference: R 0,296 - Rq 0,09). Similar behaviours have been found classifying patients with one scale and looking at the other.

\section{Conclusion}

This study showed a very good correlation between TRACE and eTRACE for the waist parameters, while for the other ones a larger sample should be study to overcome the measurement error typical of TRACE.

Published: 10 September 2010

\section{doi:10.1186/1748-7161-5-S1-O7}

Cite this article as: Pizzetti et al:: Cross-validation of TRACE and eTRACE

(Formetric TRACE) for aesthetics evaluation in scoliosis patients. Scoliosis 2010 5(Suppl 1):07.

Submit your next manuscript to BioMed Central and take full advantage of:

- Convenient online submission

- Thorough peer review

- No space constraints or color figure charges

- Immediate publication on acceptance

- Inclusion in PubMed, CAS, Scopus and Google Scholar

- Research which is freely available for redistribution

Submit your manuscript at www.biomedcentral.com/submit
C Biomed Central 